\title{
CARGA DE TRABALHO DO PROFESSOR DE EDUCAÇÃO SUPERIOR: O PROCESSO DE CONSTRUÇÃO DE UM INSTRUMENTO DE MEDIDA
}

\section{TEACHER WORKLOAD IN HIGHER EDUCATION: THE PROCESS OF CONSTRUCTING ON INSTRUMENT OF MEASUREMENT}

\author{
Francisco Hercílio de Brito Filho ${ }^{1}$ \\ Regina Heloisa Mattei de Oliveira Maciel $^{2}$ \\ Jean Mari Felizardo ${ }^{3}$
}

\section{RESUMO}

As vivências de trabalho dos professores, assim como dos trabalhadores em geral, dependem fundamentalmente das relações entre as exigências e as condições de realização do trabalho, denominadas genericamente de carga de trabalho, que é derivada do contexto e das características da organização do trabalho. A avaliação da carga de trabalho permite ampliar o grau de compreensão acerca da percepção das condições do próprio trabalho, dos riscos e dos constrangimentos dele decorrentes. $\mathrm{O}$ presente artigo caracteriza-se como um estudo metodológico com o objetivo de construir um instrumento de medida da carga de trabalho de professores de instituições de educação de nível superior. Com a finalidade de atender ao objetivo, a pesquisa utilizou técnicas de observação da atividade docente para a construção do "Questionário da Carga de Trabalho Docente de Nível Superior", o CATRA-DNS, que, ao final do presente estudo, foi composto por 39 itens, distribuídos em 3 fatores denominados físico, cognitivo e psíquico, tornando-se apto para ser submetido a processo de validação.

PALAVRAS-CHAVE: Carga de Trabalho; Docência; Educação Superior; Ergonomia.

\begin{abstract}
The work experiences of teachers, as well as workers in general, depend primarily on the relationships between the requirements and conditions in which the work is carried out, generally called workload, which derives from the context and characteristics of the work organization. The assessment of the workload allows to broaden the degree of understanding of the perception of the work conditions, risks and constraints arising therefrom. This article is characterized as a methodological study aimed at constructing an instrument of measurement of the workload of teachers from higher-level education institutions. For the purpose of fulfilling the objective, the research used techniques for observing the teaching activity for the construction of the "top level teaching workload questionnaire", the CATRADNS, which, at the end of this study, was composed of 39 items, distributed in 3 factors called physical, cognitive and psychic, becoming apt to undergo validation process.
\end{abstract}

KEYWORDS: Ergonomics; Higher Education; Teaching; Woarkload

\footnotetext{
1 Doutorando em Psicologia pela Universidade de Fortaleza (UNIFOR). Mestre em Administração pela Universidade Estadual do Ceará (UECE). Psicólogo pela Universidade Federal do Ceará (UFC). Coordenador dos cursos de graduação e pós-graduação em Administração do Centro Universitário 7 de Setembro (UNI7).

${ }^{2}$ Doutora em Psicologia pela Universidade de São Paulo (USP). Mestre em Applied Psychology Ergonomics pela University Of Wales Institute Of Science And Techonology. Graduada em Psicologia pela Universidade de São Paulo (USP). Professora titular da Universidade de Fortaleza (UNIFOR). Coordena o Núcleo de Estudos sobre o Trabalho e o Laboratório de Estudos sobre o Trabalho (LET) do Programa de Pós-Graduação em Psicologia da UNIFOR.

${ }^{3}$ Doutor em Educação pela Universidade Federal do Ceará (UFC). Mestre em Tecnologia pela Universidade Tecnológica Federal do Paraná (UTFPR). Especialista em Logística Empresarial pela Pontíficia Universidade Católica do Paraná (PUCPR). Especialista em Gestão da Aprendizagem pela Universidade Positivo (UP). Administração pela Universidade Positivo (UP). Professor do Centro Universitário 7 de Setembro (UNI7).

Revista Labor Fortaleza/CE, jan/jul 2017 Vol. 01, nº 17, p. 118-142 ISSN 1983-5000
} 


\section{INTRODUÇÃO}

No mundo atual as pessoas se organizam e se estruturam fundamentalmente em função do trabalho que constitui atividade essencial para o seu desenvolvimento. Assim também as sociedades se organizam de acordo com a dinâmica do trabalho. Daí a noção de centralidade do trabalho, que aponta para a posição nuclear que este ocupa na vida das pessoas. Dessa forma, enquanto prática social, o trabalho pode ser entendido como um ato capaz de realizar e desencadear uma associação de ações que se situam e se fundamentam em diversos espaços sociais, tanto no âmbito laboral, como nas relações familiares e de convívio na comunidade (ANTUNES, 2010).

Por ocupar a maior parte do tempo das pessoas que, muitas vezes, cumprem longas jornadas, não raro estendendo-se até a noite, com ritmo intenso, altos níveis de exigência, de atenção e concentração para a realização de tarefas e condições muitas vezes adversas, o trabalho tem gerado reações negativas nos trabalhadores, reações estas que têm se manifestado sob a forma de sofrimento, mal-estar e adoecimento.

Não é difícil, portanto, constatar várias categorias profissionais que, nesse cenário, lidam com a tensão, com a insatisfação, com a ansiedade e com o sofrimento no cotidiano do trabalho, o que tem sido comprovado por estudos nas ciências sociais, humanas e da saúde no que diz respeito à relação entre o trabalho e seus impactos na subjetividade da classe trabalhadora (FONSECA, 2001; LEMOS, 2005; SELIGMANN-SILVA, 2011; ANTUNES; PRAUN, 2015).

O trabalho do professor não está imune a essa forma perversa de organização do trabalho. A deterioração das condições físicas e psicossociais do trabalho docente tem sido apontada em alguns estudos sobre o tema (BORSOI, 2012; MAUÉS, 2010; REGO, 2014).

A forma como o trabalhador experimenta o seu trabalho está ligada à maneira como as tarefas são organizadas, definidas, divididas e distribuídas, ao modo como são estabelecidas as prescrições, assim como à forma como se operam as fiscalizações, o controle, a ordem e a hierarquia. Tudo isso compõe o conjunto de causas que ajudam a construir as impressões e os sentimentos que o professor experimenta no seu trabalho (CODO, 2002).

A organização do trabalho é, portanto, determinante na definição da carga de trabalho, que pode ser definida como o conjunto de exigências ou demandas psicobiológicas do processo de trabalho. Para a ergonomia, a carga de trabalho pode ser compreendida a partir 
de três componentes passíveis de serem mensurados: físico, cognitivo e psíquico (WISNER, 1994).

A carga de trabalho é um construto que dispõe de alguns instrumentos genéricos válidos para a sua mensuração. A despeito da relevância do papel da carga de trabalho docente, segundo pesquisa bibliográfica realizada em bases de dados, não há um número expressivo de publicações sobre a carga de trabalho docente, ao contrário do que é verificado com outras categorias profissionais, como é o caso dos trabalhadores da construção civil, de transportes, da saúde, setor bancário e, principalmente, do trabalho de enfermagem (CONISHI; GAIDZINSKI, 2007; MONTEIRO; SPIRI, 2016; QUEIJO; PADILHA, 2009; FEITOSA; LEITE; SILVA, 2012).

Em consulta realizada em setembro de 2016 nas bases de dados da Bireme e LILACS verificou-se que, entre os anos de 2010 e 2015, foram encontrados, a partir dos descritores carga de trabalho docente, treze referências, sendo duas teses de doutorado, que tratavam, respectivamente, sobre síndrome de burnout e sobre alterações vocais. Além disso, foram encontrados onze artigos publicados em periódicos científicos nacionais, dos quais seis tratavam de temas ligados a síndrome de burnout, dois tratavam de questões relativas a produção acadêmica dos professores pesquisadores, um outro artigo tratava especificamente da formação médica de estudantes de medicina e outros dois artigos abordavam fatores associados a alteração vocal de professores e prevalência de queixas vocais. Não foram encontrados artigos, dissertações ou teses brasileiras, no referido período de busca, que tratassem de instrumentos de medida da carga de trabalho docente.

Também foi realizada uma consulta em setembro de 2016 no Banco de Teses e Dissertações da Capes e, a partir dos descritores "carga de trabalho docente", verificou-se que, entre os anos de 2013 e 2016, foi defendida apenas uma tese de doutorado sobre carga de trabalho docente, que se configurou como um estudo de caso sobre a atividade docente numa instituição de educação superior privada. A pesquisa que serviu de base empírica para a referida tese não fez uso de nenhum instrumento de medida sobre a carga de trabalho docente.

Na base de dados eletrônicos do Portal Capes, utilizou-se os descritores "teaching workload", visando o acesso a produção internacional referente a carga de trabalho docente. $\mathrm{O}$ resultado desta consulta indicou sessenta e cinco ocorrências de artigos publicados em inglês entre os anos de 2014 e 2016. Cinco artigos filtrados não apresentaram nenhuma relação conceitual com carga de trabalho docente. Vinte e um artigos exploraram aspectos muito específicos da atividade docente, dentre eles, problemas de ruído no ensino de música, 
distúrbios da voz entre docentes, métodos de avaliação de desempenho docente, liderança escolar, educação infantil, educação especial e ensino para deficientes visuais, este último tendo proposto um estudo de validação de uma escala intitulada VISSIT (Escala de Intensidade Visual de Serviços do Texas). Treze artigos exploraram algum aspecto relacionado a carga de trabalho de profissionais da área de saúde, dentre os quais médicos, enfermeiros, radiologistas etc. Desses, apenas dois utilizaram o instrumento NAS (Nursing Activities Score) para avaliação da carga de trabalho entre enfermeiros. Outros vinte e seis artigos versaram sobre produtividade acadêmica, estresse entre professores universitários e satisfação no trabalho de docentes em instituições de educação superior. Os estudos apresentados nestes artigos foram feitos em vários países, a saber, Alemanha, Canadá, China, Estados Unidos, Índia, Portugal, Austrália, Estônia, Israel, Butão, Bahrein e KwalaZuluNatal, uma província da África do Sul.

Não foi verificado, na pesquisa realizada, entre os estudos internacionais, nenhuma proposição de instrumento de medida específico para mensuração da carga de trabalho docente entre professores de instituições de educação superior.

Em vista disso, é que se faz necessário estudos como este com o objetivo de construir um instrumento de medida da carga de trabalho da atividade docente, visando contribuir para o avanço do conhecimento acerca das condições e da carga desses profissionais.

Considerando a problemática até aqui exposta, estabeleceu-se o seguinte objetivo para este estudo: Construir e validar instrumento de medida da carga de trabalho de professores de instituições de educação de nível superior.

A partir das considerações apresentadas neste projeto, têm-se como principal pressuposto da pesquisa realizada: É possível a construção de um instrumento sobre carga de trabalho de docentes de instituições de educação de nível superior, composto por itens que abordam aspectos da atividade laboral desta categoria profissional.

\section{TRABALHO DOCENTE E SUAS CARGAS}

O trabalho humano pode ser compreendido a partir de três componentes: físico, cognitivo e psíquico. O componente físico corresponde ao esforço físico necessário à execução da tarefa; o componente cognitivo diz respeito ao raciocínio e ao intelecto demandados para a execução da atividade; e o componente psíquico refere-se às situações

Revista Labor Fortaleza/CE, jan/jul 2017 Vol. 01, nº 17, p. 118-142 ISSN 1983-5000 
produzidas pela dinâmica decorrente da interação do trabalhador com a organização técnica e social do trabalho. A atividade docente é considerada, numa divisão social do trabalho, como trabalho intelectual, entretanto, ela também é composta pelas cargas física e psíquica, igualmente existentes noutros tipos de atividades laborais (WISNER, 1994).

A carga física relaciona-se com a utilização do corpo no trabalho, quer seja pela necessidade de manutenção de uma determinada posição, quer seja pela realização de esforços físicos (LAURELL; NORIEGA, 1989). Movimentos repetitivos, bipedestação, adaptações a horários de trabalho com alternância de turno ou intervalos de menos de 11 horas entre uma jornada e outra, como é o caso de professores que trabalham à noite e na manhã do dia seguinte, gerando repercussões fisiológicas na alimentação e no sono do trabalhador, são exemplos de cargas físicas (FACCHINI, 1994; GRECO; OLIVEIRA; GOMES, 1999).

A carga cognitiva diz respeito ao raciocínio e ao intelecto demandados para a execução de uma determinada atividade (WISNER, 1994). Refere-se aos processos mentais, tais como percepção, memória, raciocínio e resposta motora e seus efeitos nas interações entre seres humanos e outros elementos de um sistema. Os temas mais relevantes referem-se ao estudo da carga mental de trabalho, tomada de decisão, desempenho especializado, interação homem-computador, confiabilidade humana, estresse profissional e a formação quando relacionados a projetos envolvendo seres humanos e sistemas (ABRAHÃO et al., 2009).

Os esforços cognitivos da carga de trabalho estão intrinsecamente relacionados com a atividade docente, posto que seus atributos mentais e intelectuais são ferramentas imprescindíveis para o exercício de seu ofício. Esses atributos são constantemente avaliados e postos a prova por alunos e pela própria instituição que costumam exigir um elevado nível cognitivo do professor.

A carga psíquica está relacionada ao fator afetivo ou à significação do trabalho para quem trabalha (CORREA, 2003). Elas são derivadas principalmente dos elementos do processo de trabalho que são fonte de desgaste e se relacionam com todos os elementos do processo de trabalho, portanto, com as demais cargas de trabalho. No entanto, em termos mais específicos, a principal fonte de desgaste nos processos de trabalho moderno pode ser localizada na organização e divisão do trabalho (ANTUNES, 2010).

Esse tipo de carga de trabalho se relaciona à organização da jornada de trabalho, à periculosidade do trabalho, à frequência de situações de emergência, ao grau de responsabilidade na resolução dessas situações, aos ritmos de trabalho, à pressão do tempo, ao grau de atenção e de mobilidade dentro do local de trabalho, à possibilidade de falar com os Revista Labor Fortaleza/CE, jan/jul 2017 Vol. 01, nº 17, p. 118-142 ISSN 1983-5000 
companheiros de trabalho, de tomar iniciativas e decisões a respeito de como realizar o trabalho em grupo, ao conteúdo da supervisão, ao grau de monotonia e a repetitividade das tarefas, ou à possibilidade de realizar atividades de defesa coletiva na área de trabalho (GRECO; OLIVEIRA; GOMES, 1999).

No que se refere ao contexto da atividade docente, temos verificado que os processos de ensino-aprendizagem e a própria docência vêm sofrendo modificações ao longo do tempo, sobretudo por efeito da institucionalização dos processos de formação profissional e das transformações no mundo do trabalho, que, em um contexto cada vez mais precarizado, tem priorizado um modelo produtivista, que repercute sobre as condições de vida e trabalho dos professores (LEMOS, 2005).

O modelo produtivista adotado nas instituições de educação brasileiras tem destacado a ordem publique ou pereça e, como consequência disso, temos a preocupação cada vez maior de professores, que têm sido compelidos a preocupar-se com índices, classificações, fatores de impacto, rankings e, principalmente, a lidar com situações que envolvem um grande grau de competição. Entre os principais efeitos desse modelo, destaca-se a predominância do quantitativo sobre o qualitativo, que interfere na produção científica e gera o que é denominado por "produtivismo acadêmico" (BIANCHETTI, 2010).

A universidade vem perdendo sua característica de instituição na direção de transformar-se em uma organização, onde há o primado do produtivismo como qualquer outra organização mercantil (CHAUÍ, 2003).

Uma das questões que tem sido objeto de críticas e de importantes reações diz respeito à categoria 'tempo' e ao seu redimensionamento no trabalho acadêmico. As mudanças concernentes a esta categoria, afetam os docentes de diferentes formas: tanto no aspecto institucional dos cursos e programas, quanto à produção do conhecimento (BIANCHETTI; MACHADO, 2008).

Outra questão que ajuda a compor a lógica do produtivismo acadêmico e que já faz parte do cotidiano profissional do docente são o uso das tecnologias digitais. É inegável a contribuição das tecnologias, no nosso tempo, para encurtar distâncias, abreviar tempos e, no caso da atividade docente, elas provocaram uma série de vantagens relativas ao acesso à base de dados, a possibilidades de orientação a distância, à disponibilidade de softwares ligados a educação e a pesquisa, entretanto, é notório o quanto essas estratégias possibilitam a invasão do espaço-tempo dos professores e interferem na sua vida e no seu trabalho, pois passam a ser solicitados em qualquer hora e lugar (BIANCHETTI; MACHADO, 2008).

Revista Labor Fortaleza/CE, jan/jul 2017 Vol. 01, n 17, p. 118-142 ISSN 1983-5000 
As instituições de educação, na medida em que se inserem no modelo produtivista, tendem a hierarquizar sua estrutura funcional, a exigir cumprimento de metas e padrões de desempenho funcional, gerando impactos nos níveis de autonomia dos docentes no exercício de suas atividades.

Todo professor se vincula a uma instituição de educação para realizar tarefas prescritas, como ministrar aulas, orientar pesquisas, acompanhar o desempenho de seus alunos e avaliá-los nos momentos adequados. Cabe ao professor aprovar ou reprovar o aluno, avaliando seu nível de aprendizagem em relação ao conhecimento e domínio dos conteúdos desenvolvidos ao longo da disciplina. Esta atividade envolve crítica, autocrítica e responsabilidade do professor (WENZEL, 1991; TENFEN, 1992).

Como trabalho prescrito, podemos considerar os aspectos institucionais e normativos, tanto formais como informais, que determinam o trabalho do professor. Assim, documentos produzidos pelas instituições de educação, pelo MEC, manuais didáticos, entre outros, são considerados tarefas que os professores devem realizar, sendo tomados como textos de prescrição do trabalho, ou trabalho prescrito (LOUSADA, 2006).

Dentro da perspectiva que considera que o trabalho, desde a sua prescrição até a sua realização, sofre adaptações e mudanças até se concretizar, o trabalho do professor encontra um vasto campo para explicar sua complexidade, já que ele é materializado por transformações em relação ao planejamento inicial, determinadas por vários elementos, e que causam, muitas vezes, decepções e frustrações. Assim, podemos considerar a atividade docente como capaz de transformar a prescrição da tarefa estabelecida previamente (AMIGUES, 2004), instaurando um processo dialético de renormalização constante, no qual se parte do trabalho prescrito para o real e se renormaliza o trabalho prescrito (SCHWARTZ, 2003). Esse trabalho de renormalização, reconcepção entre uma atividade e outra, configura e caracteriza o trabalho do professor (LOUSADA, 2006).

Mesmo que a autonomia do docente seja regulada pela organização do trabalho, com mecanismos de controle cada vez mais sutis, ele sempre buscará mecanismos de resistência para garantir que sua atividade se realize da forma como foi idealizada por ele. É o professor que julga o que é essencial em termos de transmissão de conhecimento, é ele quem tem a liberdade em sala de aula de administrar as atividades de acordo com seu planejamento, objetivo, senso crítico e criatividade. Esse é um dos aspectos que faz com que o trabalho do professor não se torne rotina. Mesmo que as tarefas da docência se tornem repetitivas, a forma 
de executá-las será sempre distinta, tendo em vista as distintas interações com os alunos (LEMOS, 2005).

A formação profissional do professor é confrontada com a práxis de seu trabalho, ao se vincular a um modelo produtivista de educação. O professor, nesse modelo, costuma assumir uma quantidade significativa de turmas, com um número igualmente significativo de alunos e com diversas disciplinas distintas ao longo de um mesmo período letivo. Para responder a essa elevada carga de trabalho o professor acaba por extrapolar em horas semanais a jornada prevista em seu contrato de trabalho (ESTEVE, 1999).

Além do trabalho usual de sala de aula, é necessário considerar as demais tarefas, consideradas burocráticas, como por exemplo, preparação e revisão de planos de ensino, preenchimento de listas de frequência e de notas, construção de instrumentos de avaliação dos alunos etc. Todas as atividades citadas são rotineiras, entretanto, na maioria das vezes, pouco interessantes e na maioria das vezes executadas na residência do professor

Dessa forma, percebe-se que o trabalho docente é composto de várias atividades, muitas delas sem possibilidade de decomposição e de divisão entre outros docentes, como é possível de se verificar, por exemplo, em uma linha de montagem. É um trabalho que se inicia, se constrói e termina no mesmo trabalhador.

O trabalho docente requer não somente habilidades intelectuais, mas também habilidades físicas. A realização das suas atividades dentro ou fora de sala de aula requer do professor condições físicas e psicológicas, na medida em que as mesmas envolvem esforço físico, ou seja, necessidade de força e resistência muscular para a busca de informações atualizadas, transporte de livros e materiais e ficar sentado ou em pé por tempo muitas vezes excessivamente prolongado e esforço mental para as exigências cognitivas e psíquicas inerentes à atividade (LEMOS, 2005).

A atividade do docente universitário é intensa, o que faz com que ele seja exposto, muitas vezes, a uma carga de trabalho muito elevada nos níveis físicos, psíquicos e cognitivos (ESTEVE, 1999). A jornada de trabalho é um dos elementos a serem analisados, pois apesar de regulamentada legalmente, o que se verifica é que a jornada se estende além da presença física do professor na instituição de educação, posto que a quantidade de trabalho é tão intensa que não é possível concluí-la dentro da própria instituição, obrigando-o a realizá-lo, em parte, fora do ambiente institucional, extrapolando os limites específicos da jornada regimental contratada (BORSOI, 2012). 
Seguindo a lógica do modelo neoliberal, é imposto ao professor parâmetros de produtividade que são disseminados na enorme diversidade de atividades direcionadas ao profissional. Essas atividades abrangem exigências tanto no nível intelectual, que se materializam em aulas, pesquisas, produção de artigos etc, até as exigências de ordem burocrática, como participação em reuniões de trabalho, leitura e resposta de e-mails, whatsapp etc. Além disso, o trabalho do professor possui uma especificidade que permite que, parte dele, seja realizado fora do ambiente institucional, como por exemplo, a preparação de aulas, elaboração de materiais didáticos e artigos científicos, elaboração e correção de avaliações etc., extrapolando assim a sua jornada de trabalho oficial (LOPES, 2006).

Além das atividades acima descritas existem algumas que o professor sequer contabiliza formalmente em sua jornada regimental, como por exemplo, a elaboração de relatórios ou documentos solicitados de algum setor da instituição, demandas acadêmicas ou administrativas, como atualização do currículo, ou prestação de informações atualizadas sobre sua formação ou qualificação. Ademais, um notebook ou mesmo um smartphone conectado à internet são suficientes para que o professor, onde quer que ele esteja, mantenha sua disponibilidade para a instituição. Isso implica, naturalmente, em trabalho noturno, trabalho em finais de semana e em feriados (BORSOI, 2012).

A literatura que tem discutido o trabalho docente no nível superior de educação tem afirmado, dentre outras coisas, que os professores assumem uma elevada carga de trabalho (TARDIF, 2002; ALVAREZ, 2004; MANCEBO; LOPES, 2004; LOPES, 2006; BIANCHETTI; MACHADO, 2008; BORSOI, 2012). No nível físico, tem-se relatado excessivo esforço vocal, muitas vezes com desconforto e irritação na garganta. Além disso, o professor se vê obrigado a ministrar aulas por várias horas em pé e a transportar cargas e equipamentos até a sala de aula. No nível psíquico há uma hipersolicitação direcionada ao docente por parte de alunos, coordenação e direção da instituição, conversas paralelas entre alunos, ruídos internos e externos durante as atividades acadêmicas, excesso de alunos em sala de aula, demandas da instituição pela execução de atividades administrativas e burocráticas dentro de prazos cada vez mais exíguos. No nível cognitivo é exigido do docente que este se coloque como detentor do saber, pois a sua profissão requer um certo status cognitivo e intelectual. O trabalho do professor exige que ele esteja sempre disponível para atuar como pesquisador, orientador, acolhedor para dúvidas e questionamento dos alunos, inclusão de seu nome para participação em projetos acadêmicos exigidos pelas instituições, 
conhecedor de tecnologias, visando uma preparação de aulas mais interativas e que qualifiquem melhor o aluno para o trabalho (TARDIF, 2002).

O curioso é que mesmo que as atividades dos docentes impliquem em uma elevada carga cognitiva, psíquica e física, o resultado de seu esforço é, em geral, intangível. Ministrar aulas, pesquisar, orientar alunos etc., tudo isso faz parte de uma produção na maioria das vezes invisível aos olhos da comunidade acadêmica e, mais ainda, para aqueles que estão fora desta coletividade (BORSOI, 2012).

Essa elevada carga de trabalho faz com que surja um mal-estar na profissão docente, resultado das exigências impostas pelo atual contexto social. Os principais elementos que têm causado esse mal-estar são o acelerado avanço do saber, que faz com que o professor busque aperfeiçoamento contínuo (muitas vezes a qualificação exigida é buscada com pouco ou sem nenhum apoio institucional); a constatação de que a realidade se transformou e a impossibilidade de continuar mantendo objetivos de ensino e aprendizagem que não correspondem mais ao contexto social; as exigências sociais pelo sucesso profissional dos alunos num contexto de acirramento da competitividade no mundo do trabalho (ESTEVE, 1999).

\section{OS PROCESSOS DE CONSTRUÇÃO DE INSTRUMENTOS DE MEDIDA}

A decisão de elaborar um instrumento de medida, de forma geral, parte da demanda de pesquisadores para avaliar um tema sob um novo olhar, abordar dimensões ainda não investigadas, ou aperfeiçoar um instrumento já utilizado (MOTA; PIMENTA, 2007).

A elaboração e o aperfeiçoamento de instrumentos de medida alavancam o avanço do conhecimento sobre um determinado fenômeno, noutros termos, quanto mais válidos e fidedignos são os instrumentos de medida, maior e mais confiável o conhecimento sobre o fenômeno.

$\mathrm{Na}$ constituição da base teórica faz-se necessário que o construto esteja devidamente alicerçado dentro de uma teoria. Quando há confusão no campo teórico dos construtos torna-se extremamente difícil para o pesquisador operacionalizar estes mesmos construtos.

Esta etapa, portanto, foca na teoria sobre o construto para o qual se quer desenvolver o instrumento de medida e a operacionalização do construto em itens. 
É necessário levantar uma sólida base teórica sobre o construto, que norteará a elaboração de um instrumento de medida dos comportamentos, que se referem aos traços latentes daquele construto que lhe serviu de base (PASQUALI, 1999).

O construto também deve ser dimensionado a partir da explicitação de sua estrutura interna, que pode ser entendida como os componentes da sua estrutura conceitual, de modo que o conceito/construto se torne o mais claro possível e que seja preciso o suficiente para a construção dos itens do instrumento. Neste momento, é necessário definir se o construto é uni ou multidimensional (multifatorial). Essa definição deve vir da literatura existente acerca da teoria sobre o construto (PASQUALI, 2003).

A definição conceitual ou constitutiva do construto é, portanto, considerada fundamental para a construção dos instrumentos de medida. Ela deve ser fundamentada na literatura pertinente, na opinião dos peritos da área, na experiência do próprio pesquisador e na análise de conteúdo do construto (PASQUALI, 1999).

A definição constitutiva do construto é concebida em termos dos conceitos próprios da teoria em que ele se insere, dando-lhe os limites que ele possui. Ela contempla o terreno da teoria, da abstração (PRIMI; MUNIZ; NUNES, 2009).

Além da definição constitutiva, o construto também deverá ser definido operacionalmente, na medida em que possibilitará a passagem da abstração para o nível concreto. A operacionalização de um construto deve ser definida em termos de comportamentos através dos quais se expressa o construto. Este é o momento mais crítico na construção de medidas, pois é aí que se fundamenta a validade do instrumento e nisso se baseia a legitimidade da representação empírica e comportamental dos construtos (PASQUALI, 1998).

A fase de construção dos itens que comporão o instrumento é representada pela operacionalização do construto que será definido em termos comportamentais. Os itens são a expressão da representação comportamental do construto, a resposta que o sujeito dará a um estímulo que lhe será apresentado (PASQUALI, 2003).

A operacionalização do construto deve estar amparada na literatura pertinente sobre este construto, na opinião de peritos na área e na experiência do próprio pesquisador. $\mathrm{O}$ construto é operacionalizado através da construção dos itens, que são a expressão da representação comportamental do construto, ou seja, os itens que os sujeitos terão de responder para que possa ser feita a avaliação da magnitude da presença do construto (PASQUALI; MOURA; FREITAS, 2010). 
Para a construção dos itens, Pasquali; Moura e Freitas (2010) recomenda alguns critérios importantes a serem observados:

1. critério comportamental - o item deve expressar um comportamento e não uma abstração;

2. critério de objetividade - o item deve expressar objetivamente a preferência do sujeito;

3. critério da simplicidade - o item deve expressar uma única ideia. Por exemplo: gosto de maçã; e não gosto de maçã porque é saudável;

4. critério de clareza - o item deve ser inteligível para todos os estratos da população meta. Sugere-se a utilização de frases curtas, com expressões simples e inequívocas;

5. critério da relevância - o item deve ser consistente com o construto e com os outros itens que cobrem o mesmo fator. Este critério diz respeito a carga fatorial na análise fatorial que o item possui com o fator e que constitui a covariância (correlação);

6. critério de precisão - o item deve possuir uma posição definida no contínuo do construto, sendo distinto dos demais itens que cobrem o mesmo contínuo. Também deve possuir um desvio-padrão reduzido;

7. critério de variedade - o item deve variar a linguagem para evitar a confusão das frases, a dificuldade de diferenciá-las, além da monotonia e do cansaço dos sujeitos;

8. critério da modalidade - o item deve ser formulado com frases de reação modal, evitando assim expressões extremadas, que provocam respostas viciadas;

9. critério de amplitude - o conjunto dos itens referentes a um mesmo fator deve cobrir toda a extensão de magnitude do contínuo desse fator;

10. critério de equilíbrio - os itens do mesmo fator devem cobrir igualmente todos os segmentos do contínuo, devendo haver itens fracos, moderados e extremos, obedecendo uma distribuição que se assemelha a da curva normal.

\section{MÉTODO}

O estudo presente refere-se à construção de instrumento de medida da carga de trabalho de professores de instituições de nível superior. Para isto, foram realizadas Revista Labor Fortaleza/CE, jan/jul 2017 Vol. 01, nº 17, p. 118-142 ISSN 1983-5000 
observações da atividade docente, com registros no Protocolo de Observação da Atividade Docente que serviram de base para a elaboração do Questionário da Carga de Trabalho Docente de Nível Superior - CATRA-DNS.

Este é um estudo metodológico que se caracteriza por investigar, organizar e analisar dados para construir, validar e avaliar instrumentos e técnicas de pesquisa, centrada no desenvolvimento de ferramentas específicas de coleta de dados com vistas a melhorar a confiabilidade e a validade desses instrumentos. É o estudo que se refere à elaboração de instrumentos de captação ou de manipulação da realidade. Está, portanto, associada a caminhos, formas, maneiras e procedimentos para atingir determinado fim (MORESI, 2003).

O desenvolvimento deste estudo para a construção de um instrumento de medida da carga de trabalho de professores de nível superior tem como objetivos futuros as validações nos campos semântico, de construto e estatístico (PASQUALI, 1998, 1999, 2003, 2007, 2009; PASQUALI; MOURA; FREITAS, 2010).

\section{Participantes}

Os sujeitos deste estudo foram compostos por pessoas que atenderam aos seguintes critérios de inclusão:

a. ser docente de instituição de educação superior;

b. aceitar participar da pesquisa e assinar o Termo de Consentimento Livre e Esclarecido.

O estudo contou com uma amostra de 18 docentes de instituições de educação superior, onde, no período entre 22 de abril e 19 de agosto de 2015, foram realizados os procedimentos previstos nesta etapa da pesquisa.

A pesquisa foi aplicada em professores lotados em instituições de educação superior, públicas e privadas, que aderiram voluntariamente ao estudo. Para efeito deste estudo foram feitos contatos com dirigentes e coordenadores de instituições de educação superior, visando obter a autorização para a realização desta pesquisa naquelas instituições.

\section{Instrumentos}


Para esta pesquisa foi construído um Protocolo de Observação da Atividade Docente, visando a observação sistemática dos principais aspectos das atividades desenvolvidas pelo docente de nível superior.

O Protocolo de Observação da Atividade Docente foi o instrumento que permitiu o registro das observações realizadas em campo, visando a captação de elementos que compuseram os itens da escala.

O Protocolo de Observação da Atividade Docente contou com 10 itens, compostos de variáveis como: nome da instituição, curso, disciplina, horário da aula, caracterização do ambiente (distribuição do espaço físico, condições de iluminação, de ventilação e de temperatura e acústica), indicadores de cargas físicas (exigências físicas vivenciadas no trabalho), indicadores de cargas psíquicas (exigências psicológicas vivenciadas no trabalho).

As análises dos Protocolos de Observação da Atividade Docente resultaram nos itens que compuseram a escala de carga de trabalho dos docentes de nível superior.

\section{Procedimentos}

O estudo teve como objetivo construir um instrumento de medida da carga de trabalho de professores de instituições de nível superior, o CATRA-DNS.

Para isso, foram acompanhadas 36 horas de aulas em diversos cursos de nível superior de quatro instituições de educação superior. Cada aula assistida foi, portanto, registrada no Protocolo de Observação da Atividade Docente.

O Protocolo de Observação de Campo foi preenchido com base nas aulas acompanhadas pelo pesquisador, junto aos 18 professores participantes. No final de todas as aulas acompanhadas, foi feito contato com o respectivo professor, buscando estabelecer uma troca de percepções sobre a aula assistida, de forma a possibilitar uma ampliação das impressões coletadas. Foram acompanhadas aulas em 6 cursos de graduação e 2 cursos de pós-graduação de 4 instituições de educação superior, sendo 2 instituições públicas e 2 instituições particulares. As aulas acompanhadas classificavam-se como aulas práticas e aulas teóricas, todas com 2 horas aula, totalizando 36 horas de observação de campo.

O Protocolo de Observação de Campo forneceu os dados empíricos, coletados a partir da observação da atividade docente, para a construção do instrumento piloto do CATRA-DNS e considerou elementos ligados aos aspectos físicos do ambiente de trabalho, 
aos aspectos da organização do trabalho e aos aspectos psicossociais da relação do professor com o seu trabalho. No que tange aos aspectos físicos do ambiente de trabalho foram abordadas questões como: iluminação, temperatura, ventilação e ruído. Quanto aos aspectos da organização do trabalho as questões orbitaram em temas como autonomia, responsabilidades, pressões, solicitações, administração do tempo, exigências de postura, relacionamentos entre pares e alunos e demais dificuldades percebidas pelos professores no exercício da atividade docente. No que se refere aos aspectos psicossociais da relação do professor com o seu trabalho, o CATRA-DNS abordou a relação do professor com chefia, colegas e natureza do trabalho.

Além das observações presenciais da atividade docente, a elaboração do CATRADNS tomou a Ergonomia como base teórica, na medida em que foi estruturado a partir dos componentes físico, cognitivo e psíquico da carga de trabalho (WISNER, 1994). O componente físico considerou os elementos de natureza fisiológica envolvidos na execução da tarefa; o componente cognitivo levou em consideração aspectos relacionados ao raciocínio e ao intelecto demandados para a execução da atividade e; o componente psíquico considerou os aspectos relacionado a dinâmica decorrente da interação do trabalhador com a organização técnica e social do trabalho.

A pesquisa foi registrada junto ao Comitê de Ética da Universidade de Fortaleza e os aspectos éticos que garantem a integridade dos participantes deste estudo estão assegurados com base na Resolução n. 466/2012 do Conselho Nacional de Saúde/Brasil. A mesma foi aprovada em 11 de maio de 2016, CAAE: 44967215.2.0000.5052.

A anuência ao termo de consentimento livre e esclarecido foi pré-requisito para a o acompanhamento das aulas dos professores durante a Observação de Campo, de modo que a participação na pesquisa só foi possível após o sujeito ter assinado o termo de consentimento livre e esclarecido, atestando a sua anuência em participar da mesma, declarando que compreendeu seus objetivos, a forma como ela seria realizada, os riscos e benefícios envolvidos, o seu anonimato e o direito do mesmo em recusar ou abandonar a participação na pesquisa em qualquer momento.

\section{RESULTADOS}

Neste tópico são apresentados os principais resultados dos processos de construção do Questionário da Carga de Trabalho Docente de Nível Superior - CATRA-DNS. 
Para a definição dos indicadores que, o Protocolo de Observação da Atividade Docente foi o instrumento utilizado para a definição das variáveis que compõem as cargas físicas, cognitivas e psíquicas do Questionário da Carga de Trabalho Docente de Nível Superior - CATRA-DNS.

\section{Mapeamento dos Indicadores da Carga Física da Atividade Docente}

Os indicadores de carga física foram mapeados no Protocolo de Observação da Atividade Docente, na questão que se referia à carga física do trabalho. Desta forma, conforme Tabela 1, foram registrados os seguintes indicadores durante as observações realizadas em campo.

Tabela 1 - Indicadores mapeados sobre a carga física da atividade docente

\begin{tabular}{l} 
Indicadores físicos do trabalho docente \\
\hline Condições de iluminação do ambiente de trabalho \\
Condições de ruídos do ambiente de trabalho \\
Condições de ventilação do ambiente de trabalho \\
Condições de temperatura do ambiente de trabalho \\
Distribuição do espaço físico do ambiente de trabalho \\
Condições de postura física no exercício da atividade docente \\
Condições físicas e corporais no exercício da atividade docente \\
Fonte: elaborado pelos autores.
\end{tabular}

O mapeamento feito a partir do Protocolo de Observação da Atividade Docente constatou as condições de iluminação, de ruídos, de ventilação, de temperatura, de distribuição do espaço físico da sala de aula, de postura física e de condições físicas e corporais no exercício da atividade como indicadores importantes na determinação da carga física do trabalho docente.

\section{Mapeamento dos Indicadores da Carga Cognitiva da Atividade Docente}

O Protocolo de Observação da Atividade Docente também mapeou os indicadores da carga cognitiva da atividade docente. A Tabela 2 apresenta os indicadores registrados. 
Tabela 2 - Indicadores mapeados sobre a carga cognitiva da atividade docente

\begin{tabular}{l}
\hline Indicadores cognitivos da atividade docente \\
\hline Planejamento para o exercício da atividade docente \\
Atenção concentrada para o exercício da atividade docente \\
Criatividade para o exercício da atividade docente \\
Raciocínio lógico para o exercício da atividade docente \\
Memória para o exercício da atividade docente \\
Conhecimento técnico e conceitual específicos para o exercício da atividade docente \\
Atividade intelectual para o exercício da atividade docente \\
\hline
\end{tabular}
Fonte: elaborado pelos autores.

O Protocolo de Observação da Atividade Docente constatou que, para o exercício da atividade docente, são necessários domínios cognitivos de planejamento, atenção concentrada, criatividade, raciocínio lógico, memória, conhecimento técnico e conceitual, assim como utilização do intelecto. Esses indicadores foram considerados fundamentais para a determinação da carga cognitiva do trabalho docente.

\section{Mapeamento dos Indicadores da Carga Psíquica da Atividade Docente}

Os indicadores de carga psíquica foram mapeados no Protocolo de Observação da Atividade Docente. Desta forma, conforme Tabela 3, foram registrados os seguintes indicadores durante as observações de campo.

Tabela 3 - Indicadores mapeados sobre a carga psíquica da atividade docente

\begin{tabular}{l}
\hline Indicadores psíquicos do trabalho docente \\
\hline Condições de relacionamento humano com chefia, pares e alunos no contexto do trabalho \\
Condições de atendimento de demandas no contexto do trabalho \\
Condições de equilíbrio mental para o exercício do trabalho \\
Pressão de tempo para realização do trabalho \\
Determinação de metas de desempenho no contexto do trabalho \\
Realização de atividades em dias e horários atípicos \\
Condições de valorização da profissão docente
\end{tabular}
Fonte: elaborado pelos autores.

O mapeamento feito a partir do Protocolo de Observação da Atividade Docente apontou os seguintes indicadores psíquicos do trabalho docente: condições de relacionamento humano com chefia, pares e alunos no contexto do trabalho, condições de atendimento de 
demandas no contexto do trabalho, condições de equilíbrio mental para o exercício do trabalho, pressão de tempo para realização do trabalho, existência de práticas de definição de metas de desempenho no contexto do trabalho, realização de atividades em dias e horários atípicos, e condições de valorização da profissão docente.

O conjunto de indicadores físicos, cognitivos e psíquicos mapeados a partir da aplicação do Protocolo de Observação da Atividade Docente definiu a versão piloto do Questionário da Carga de Trabalho Docente de Nível Superior - CATRA-DNS e determinou o alcance do objetivo traçado para este estudo, a saber, construir um instrumento de medida da carga de trabalho de professores de instituições de nível superior.

O estudo foi finalizado com a versão piloto do CATRA-DNS, que foi elaborado inicialmente com 39 itens ao todo, sendo 13 itens relacionados aos aspectos da carga física (F) de trabalho, 13 itens relacionados diretamente aos aspectos da carga cognitiva (C) de trabalho e 13 itens com componentes de carga psíquica (P), conforme apresentado na Tabela 4.

\section{Tabela 4 - Itens da versão piloto do CATRA-DNS}

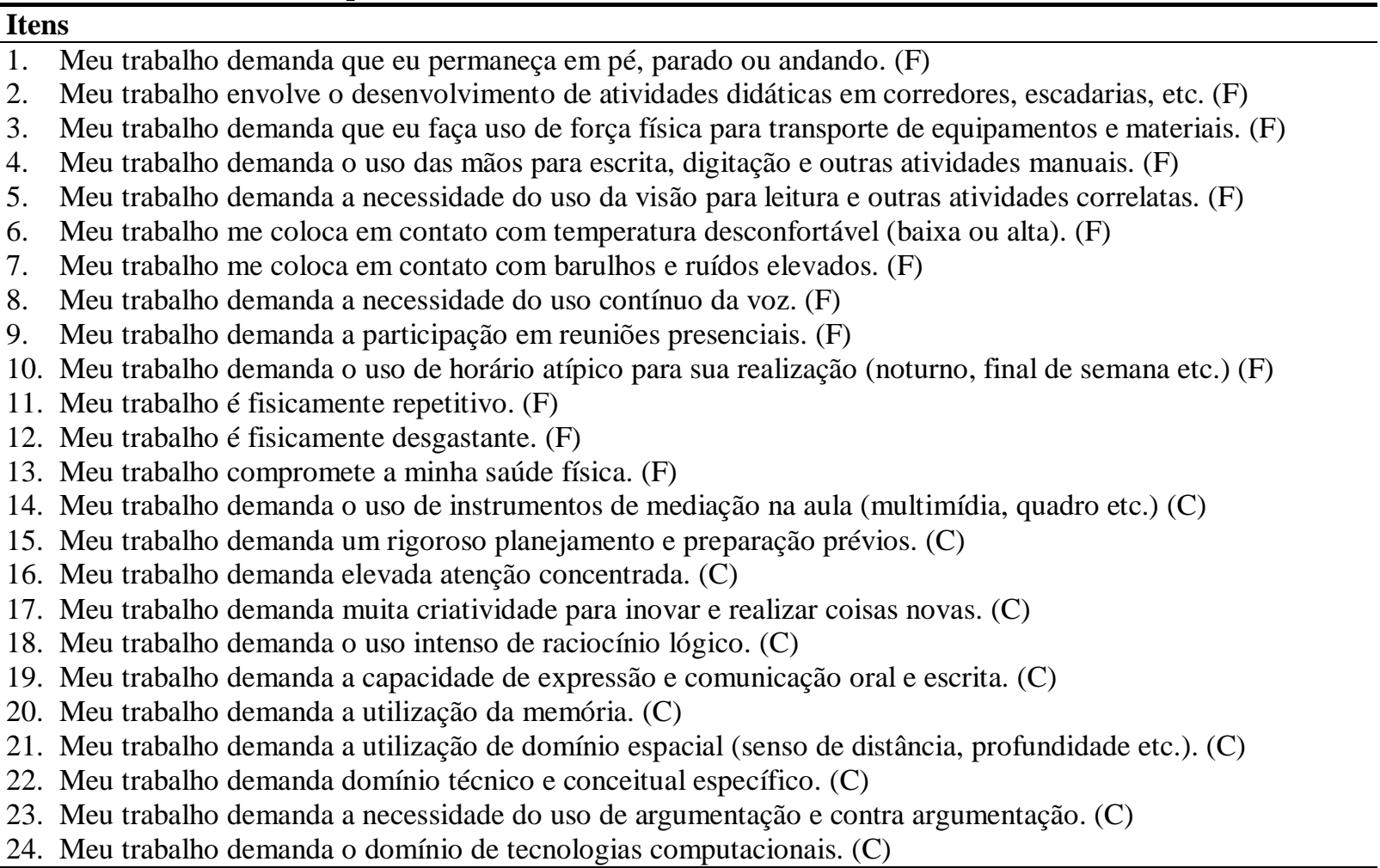


25. Meu trabalho demanda a minha atualização continuada em programas de formação profissional. (C)

26. Meu trabalho é cognitivamente desgastante. (C)

27. Meu trabalho demanda a necessidade de relacionamento com uma grande quantidade de pessoas. $(\mathrm{P})$

28. Meu trabalho demanda atuação em muitas turmas. (P)

29. Meu trabalho exige que eu atenda demandas e solicitações feitas por alunos. (P)

30. Meu trabalho exige que eu atenda demandas e solicitações feitas pela minha Coordenação. (P)

31. Meu trabalho demanda a necessidade de elevado equilíbrio mental. (P)

32. Meu trabalho demanda o uso de senso de justiça. (P)

33. Meu trabalho gera pressão com relação a cumprimento de prazos. (P)

34. Meu trabalho demanda a orientação e supervisão de alunos (monografias e estágios profissionais). (P)

35. Meu trabalho demanda produtividade (publicação de artigos, participação em congressos etc.). (P)

36. Meu trabalho demanda a necessidade de lidar com desinteresse e desmotivação dos alunos. (P)

37. Meu trabalho é mentalmente repetitivo. (P)

38. Meu trabalho me coloca em situação de estresse elevado. (P)

39. Meu trabalho compromete a minha saúde mental. (P)

Fonte: elaborado pelos autores.

\section{CONCLUSÃO}

O presente estudo estabeleceu como objetivo geral construir um instrumento de medida da carga de trabalho de professores de instituições de educação de nível superior.

O estudo apresentou resultados satisfatórios e, ao seu final, foi apresentada uma versão do CATRA-DNS com 39 itens a serem submetidos futuramente aos processos de validação.

Foi estabelecido como pressuposto que seria possível a construção de um instrumento sobre carga de trabalho de docentes de instituições de educação de nível superior, composto por itens que abordam aspectos da atividade laboral desta categoria profissional. Como demonstrado, o referido pressuposto foi confirmado com a apresentação da versão inicial do CATRA-DNS composto por 39 itens.

Os resultados deste estudo, no que dizem respeito ao objetivo inicialmente definido, permitiram concluir que o CATRA-DNS mostrou-se um instrumento apto para ser submetido a processo de validação de construto, validação semântica e validação psicométrica, estudos a serem realizados em sequência.

O processo de construção do CATRA-DNS resultou na elaboração de um instrumento composto por de 39 itens que foram, teoricamente, distribuídos em 3 fatores, sendo 13 itens relacionados aos aspectos da carga física de trabalho, 13 itens relacionados diretamente aos aspectos da carga cognitiva de trabalho e 13 itens com componentes de carga psíquica.

É válido destacar o desafio enfrentado no desenvolvimento desse estudo, dada a complexidade e subjetividade do construto carga de trabalho, que envolve uma gama de Revista Labor Fortaleza/CE, jan/jul 2017 Vol. 01, nº 17, p. 118-142 ISSN 1983-5000 
conceitos, variáveis, perspectivas e, ao mesmo tempo, a escassez de instrumentos de medidas deste construto aplicados à categoria docente. Entretanto, a efetividade do emprego dos conhecimentos teóricos da ergonomia e das orientações técnicas da psicometria, em estudos desta natureza, possibilitou a construção de um instrumento de medida de carga de trabalho aplicado especificamente para docentes de instituições de educação de nível superior.

A construção de instrumentos de medida, especialmente daqueles destinados à mensuração de fenômenos subjetivos, é um processo longo que demanda o desenvolvimento de estudos longitudinais e sequenciais, não sendo encerrado apenas na presente pesquisa. Estudos sobre a mensuração da carga de trabalho em docentes de instituições de nível superior ainda são incipientes no nosso contexto. Assim sendo, esta pesquisa é entendida como um ponto de partida para outras dessa natureza, considerando que contribui para o desenvolvimento da teoria sobre carga de trabalho docente. A partir desses resultados, futuras pesquisas poderão ser desenvolvidas, a fim de se aprimorar a compreensão da temática e de oferecer subsídios para a implementação de intervenções que visem, efetivamente, a promoção de ambientes de trabalho menos degradantes para o trabalhador docente.

Considera-se, portanto, a necessidade de novos estudos, especialmente visando a validação do CATRA-DNS. A realização de novos estudos pode servir para aprofundar a análise do fenômeno carga de trabalho em docentes, a partir da sua correlação com outras variáveis, como, por exemplo, o processo de saúde e adoecimento e as eventuais condições epidemiológicas da categoria.

Em síntese, a despeito das eventuais limitações, este estudo conseguiu alcançar o objetivo definido para ele, a saber, o de construir um instrumento de medida da carga de trabalho de professores de instituições de educação de nível superior. Entretanto, para além dos objetivos formais da pesquisa, foi possível evidenciar, ao longo deste estudo, o contexto de um trabalho precarizado e caracterizado pela lógica da hiperprodutividade acadêmica em que estão submetidos os docentes de instituições de educação superior e estudos como este, somados a outros que poderão se agregar no futuro, servem para denunciar o contexto de depreciação e degradação do trabalho docente e sensibilizar seus atores para a construção de um contexto de trabalho menos degradante e com maior plenitude de sentido.

\section{REFERÊNCIAS BIBLIOGRÁFICAS}


ABRAHÃO, J.; SZNELWAR, L.; SILVINO, A.; SARMET, M.; PINHO, D. Introdução à ergonomia: da prática à teoria. São Paulo: Blucher, 2009.

ALVAREZ, D. Cimento não é concreto, tamborim não é pandeiro, pensamento não é dinheiro! Para onde vai a produção acadêmica? Rio de Janeiro: Myrrha, 2004.

AMIGUES, R. Trabalho do professor e trabalho de ensino. In: MACHADO, A. R. (Org.). O ensino como trabalho: uma abordagem discursiva. Londrina: Eduel, 2004. p. 35-53.

ANTUNES, R. Adeus ao trabalho? Ensaio sobre as metamorfoses e a centralidade do mundo do trabalho. São Paulo: Cortez, 2010.

ANTUNES, R.; PRAUN, L. A sociedade dos adoecimentos no trabalho. Serviço Social e Sociedade, São Paulo, n. 123, 2005, p. 407-427.

BIANCHETTI, L. O processo de Bolonha e a intensificação do trabalho na universidade: entrevista com Josep M. Blanch. Educação \& Sociedade. Campinas: CEDES, v. 31, n. 110, 2010, p. 263-286.

BIANCHETTI, L.; MACHADO, A. M. N. "Reféns da produtividade": sobre produção de conhecimento, saúde dos pesquisadores e intensificação do trabalho na pós-graduação. In: Anais da 30 ${ }^{\text {a }}$ Reunião Anual da ANPEd. Rio de Janeiro: ANPEd. 2008.

BORSOI, I. C. F. Trabalho e produtivismo: saúde e modo de vida de docentes de instituições públicas de ensino superior. Cadernos de Psicologia Social do Trabalho, 15(1), 2012, p. 81100.

CHAUÍ, M. A universidade pública sob nova perspectiva. Revista Brasileira de Educação. Rio de Janeiro: ANPEd, 24, 2003, p. 5-15.

CODO, W. Educação, carinho e trabalho: burnout, a síndrome da desistência do educador, que pode levar à falência da educação. Petrópolis: Vozes, 2002. 
CONISHI, R. M. Y.; GAIDZINSKI R. R. Nursing Activities Score-NAS como instrumento para medir carga de trabalho de enfermagem em UTI adulto. Rev Esc Enferm USP. 41(3), 2007, p. 346-354.

CORREA, F. P. Carga mental e ergonomia. Dissertação (Mestrado em Engenharia de Produção), Programa de Pós-Graduação em Engenharia de Produção. Florianópolis, UFSC. 2003.

ESTEVE, J. M. Mal-estar docente: a sala de aula e a saúde dos professores. São Paulo: EDUSC, 1999.

FACCHINI, L. A. Uma contribuição da epidemiologia: o modelo de determinação social aplicado à saúde do trabalhador. In: BUSCHINELLI, J. T.; ROCHA, L. E.; RIGOTTO, R. M. (Orgs.). Isto é trabalho de gente?: vida, doença e trabalhador no Brasil. Petrópolis: Vozes, 1994, p. 40-59.

FEITOSA, M. C.; LEITE, I. R. L.; SILVA, G. R. F. Demanda de intervenções de enfermagem a pacientes sob cuidados intensivos: nas nursing activities score. Escola Anna Nery UFRJ. 16(4), 2012, p. 682-688.

FONSECA, C. C. O. P. O adoecer psíquico no trabalho do professor do ensino fundamental e médio da rede pública no estado de Minas Gerais. Dissertação (Mestrado em Engenharia de Produção), Programa de Pós-Graduação em Engenharia de Produção. Florianópolis: UFSC. 2001.

GRECO, R. M.; OLIVEIRA, V. M.; GOMES, J. R. Cargas de trabalho dos técnicos operacionais da escola de enfermagem da Universidade de São Paulo. Revista Brasileira de Saúde Ocupacional, 95/96(25), 1999, p. 59-75.

LAUREll, A. C.; NORIEGA, M. Processo de produção e saúde: trabalho e desgaste operário. São Paulo: Hucitec, 1989. 
LEMOS, J. C. Cargas psíquicas no trabalho e processos de saúde em professores universitários. Tese (Doutorado em Engenharia de Produção), Programa de Pós-Graduação em Engenharia de Produção, Universidade Federal de Santa Catarina. Florianópolis, UFSC. 2005 .

LOPES, M. C. R. "Universidade produtiva" e trabalho docente flexibilizado. Estudos e Pesquisas em Psicologia, 6(1), 2006, p. 35-48.

LOUSADA, E. G. Entre trabalho prescrito e realizado: um espaço para a emergência do trabalho real do professor. Tese (Doutorado em Linguística Aplicada e Estudos da Linguagem), Pontifícia Universidade Católica de São Paulo. São Paulo, PUC-SP. 2006.

MANCEBO, D.; LOPES, M. C. R. Trabalho docente: compressão temporal, flexibilidade e prazer? Revista de Educação Pública, 13(24), 2004, p. 138-152.

MAUÉS, O. A reconfiguração do trabalho docente na educação superior. Educar em Revista, (Esp. 1), 2010, p. 141-160.

MONTEIRO, L. M.; SPIRI, W. C. Indicadores de qualidade e carga de trabalho uma revisão integrativa em enfermagem. Revista Mineira de Enfermagem (REME), 20(e936), 2016, p. $1-8$.

MORESI, E. A. D. Manual de metodologia da pesquisa. Brasília: UCB, 2003.

MOTA, D. D. C. F.; PIMENTA, C. A. M. Avaliação e mensuração de variáveis psicossociais: desafio para pesquisa e clínica de enfermagem. Revista Gaúcha de Enfermagem, 8(3), 2007, p. 309-314.

PASQUALI, L. Princípios de elaboração de escalas psicológicas. Revista de Psiquiatria Clínica, 25(5), 1998, p. 206-213.

Instrumentos psicológicos: manual prático de elaboração. Brasília: LamPAM, 1999. 
Psicometria: teoria dos testes na psicologia e na educação. v. 1. Petrópolis: Vozes, 2003

. Validade dos testes psicológicos: será possível reencontrar o caminho? Psicologia, Teoria e Pesquisa, 23(Esp.), 2007, p. 99-107.

Psicometria. Revista da Escola de Enfermagem USP, 43(Esp.), 2009, p. 992-999.

PASQUALI, L.; MOURA, C. F.; FREITAS, L. C. O. Instrumentação psicológica: fundamentos e práticas. Porto Alegre: Artmed, 2010.

PRIMI, R.; MUNIZ, M.; NUNES, C. H. S. Definições contemporâneas de validade de testes psicológicos. Avanços e polêmicas em avaliação psicológica, 1, 2009, p. 243-265.

QUEIJO, A. F.; PADILHA, K. G. Nursing Activities Score (NAS): adaptação transcultural e validação para a língua portuguesa. Rev Esc Enferm USP. 43(n esp.), 2009, p. 1009-1016.

REGO, T. C. Produtivismo, pesquisa e comunicação científica: entre o veneno e o remédio. Educação e Pesquisa, 40(2), 2014, p. 325-346.

SCHWARTZ, Y. Le langage en travail. In: SCHWARTZ, Y.; DURRIVE, L. (Org.). Travail et ergologie: entretiens sur l'activité humaine. Toulouse: Octarès, 2003. p. 131-148.

SELIGMANN-SILVA, E. Desgaste mental no trabalho dominado. São Paulo: Cortez, 2011.

TARDIF, M. Saberes docentes e formação profissional. Petrópolis: Vozes, 2002.

TENFEN, W. O processo de (des)qualificação do professor. Dissertação (Mestrado em Educação) - Programa de Pós-Graduação em Educação, Universidade Federal de Santa Catarina. Florianópolis, UFSC, 1992. 
WENZEL, R. L. O professor e o trabalho abstrato: uma análise da (des)qualificação do professor. Dissertação (Mestrado em Educação) - Programa de Pós-Graduação em Educação, Universidade Federal de Santa Catarina. Florianópolis, UFSC, 1991.

WISNER, A. A inteligência no trabalho: textos selecionados de ergonomia. São Paulo: FUNDACENTRO, 1994. 